\title{
Removal of direct and reactive dyes from textile wastewater using Moringa stenopetala seed extract
}

\begin{abstract}
With textile wastewater being one of the most sources of pollution containing higher value of colour, BOD, COD and several pollutants, brings serious problem to the ecological environment. This study maily focused on evaluating the efficacy of removal of reactive dyes, direct dyes, mixture of dye wastes and mixture of industrial and dye wastewaters by the natural absorbent Moringa. The seeds of Moringa tree contain a coagulant protein that can be used for treatment of wastewater. Seed extracts (coagulant) obtained by two methods viz. simple extraction with distilled water and with saline water have been used for the study. The effect of some operating parameters on coagulation namely $\mathrm{pH}$, coagulant dosage, mixing time, colour removal and turbidity was studied. It was observed that the colour removals in direct red and reactive red dyes are 94.45 and $98.4 \%$ respectively with simple extract of seeds done with distilled water and it was in the order of 96.6 and $97.3 \%$ respectively with saline extracts of the seed. These values of colour removal of dyes are optimized at $70 \mathrm{ml} / \mathrm{L}$ of coagulant and $\mathrm{pH} 10$. The mixture of industrial wastewater and dye wastes, colour removal and turbidity removal was $85.8 \%$ with simple extract and $53 \%$ with saline extract respectively at optimized point. Moringa stenopetala seed extract has high removal ability for anionic dyes.
\end{abstract}

Keywords: moringa stenopetala, natural coagulant, colour removal, wastewater, treatment; coagulation, flocculation
Volume 5 Issue 4 - 2019

\section{Gemeda Gebino Gelebo, Fitsum Etefa Ahmed}

Ethiopian Institute of Textile and Fashion Technology (EiTEX), Bahir Dar University, Ethiopia

\author{
Correspondence: Mr. Fitsum Etefa Ahmed, Leather \\ Engineering Department Program Head, Ethiopian Institute of \\ Textile and Fashion Technology (EiTEX), Bahir Dar University, \\ Bahir Dar, Ethiopia, Tel +251917101452, \\ Email Oneday790@gmail.com
}

Received: May 03, 2019 | Published: July 05, 2019
Abbreviations: $\mathrm{PACl}$, polyaluminium chloride; $\mathrm{pH}$, potential of hydrogen; BOD5, biological oxygen demand in 5; COD, chemical oxygen demand; SPSS, statistical package for the social sciences; SRP, soluble reactive phosphorus; TDS; total dissolved solid; TSS, total suspended solid

\section{Introduction}

Dyes in Textile waste water are considered as the most pollutants. High volume of waste water that is produced by the textile industry causes water pollution. Generally, dyes in waste water from textile and dyestuff industries are difficult to remove. This is because dyes are synthetic material and have complex aromatic structures, which make them more stable and difficult to biodegrade. ${ }^{1}$ The removal of dyes from textile waste water is one of the most environmental challenges. In order to remove dyes from wastewater, different researches procedure are developed; for example, physical and chemical degradation and adsorption onto materials such activated carbon. ${ }^{2}$ The most commonly used in the textile industry are chemical methods that use oxidizing agents such as, peroxide of hydrogen, ozone and purification by physicochemical process of coagulation- flocculation, in which chemical compounds are used, the most employed are iron and aluminum salts. This physicochemical process is widely used both in developed countries as in developing, for it easy operation and low cost. Nevertheless, when applied in textile wastewater, it generates large volumes of sewage sludge and the ineffective decoloration of some soluble dyes.

Moringa tree belongs to the family Moringaceae, which is shrubs trees cultivated across the tropical belt including Ethiopia, used for a variety of purposes such as food, medicinal, and others. ${ }^{3}$ The seeds of the Moringa tree contain a coagulant protein that can be used in the treatment of industrial wastewater. For drinking water clarification, a Moringa seed is also used as coagulant/flocculent agent, due to its high content of a water-soluble cationic protein, which able to reduce turbidity. Oil extracted from Moringa can be used for drinking water clarification and textile wastewater treatment. ${ }^{4}$ The use of natural coagulant is increasing as substitution of external chemical coagulants such as aluminum sulfate and ferric chloride. Water soluble dry Moringa seeds extract is one of the natural coagulants. Moringa is used for water treatment as source of activated carbon and produce a product working as a coagulant/flocculant agent.

At low temperature working conditions, performance of these customary chemical coagulants is dubious and on-going developments have resulted in the introduction of polymerized aluminium coagulants. Owing to its higher superiority and lower consumption of alkalinity, Polyaluminium chloride $(\mathrm{PACl})$ has garnered a growing market. Flocculants such as the more common polyacrylamide, which are organic synthetic polymer available in the market, offers a wider selection of chemical coagulants to cater for the diverse requirements of the individual water treatment plants. ${ }^{5}$ At this time, there is an increased interest in the decolorization and decontamination of industrial textile wastewater. Different wastewater treatment technologies have been studied, in order to solve the problems caused by the toxic substances contained in industrial textile wastewater, such as electrocoagulation, adsorption, photocatalytic process, ozonation, membrane bioreactor and anaerobic/aerobic biological treatment. However, these methods are neither economically nor technologically suitable for large scale use and normally require the combination of two or three methods to achieve an appropriate level of colour removal. ${ }^{6-8}$ The various coagulants attempted for colour removal and their efficiencies are listed in Table 1. In order to overcome the side effect of inorganic coagulants and artificial polymers related with growing environmental concerns worldwide, there is a need to think about other possible alternatives for textile wastewater. Therefore, 
researchers have shown considerable interest to use natural polymers as coagulants in the recent past. .,9-10 $^{5,1}$

Table I Buffer solutions used in the study

\begin{tabular}{ll} 
pH & Chemicals for buffer solution preparation \\
\hline 2 & $50 \mathrm{ml} 0.2 \mathrm{M} \mathrm{KCl}+13 \mathrm{ml}$ of $0.2 \mathrm{M} \mathrm{HCl}$ \\
4 & $21 \mathrm{I.75} \mathrm{ml} 0.1 \mathrm{M}$ acetic acid $+38.25 \mathrm{ml}$ of $0.1 \mathrm{M}$ sodium acetate \\
6 & $13.05 \mathrm{ml} 0.1 \mathrm{M}$ acetic acid $+236.95 \mathrm{ml}$ of $0.1 \mathrm{M}$ sodium acetate \\
8 & $\begin{array}{l}100 \mathrm{~mL} 0.025 \mathrm{M} \mathrm{Na} 2 \mathrm{~B} 4 \mathrm{O} 7.10 \mathrm{H} 2 \mathrm{O} \text { (borax) }+4 \mathrm{Imls} \text { of } 0.1 \mathrm{M} \\
\mathrm{HCl} .\end{array}$
\end{tabular}

$10 \quad 100 \mathrm{ml} 0.05 \mathrm{M} \mathrm{NaHCO}+21.4 \mathrm{mls}$ of $0.1 \mathrm{M} \mathrm{NaOH}$

$1250 \mathrm{~mL} 0.2 \mathrm{M} \mathrm{KCl}+12 \mathrm{ml} 0.2 \mathrm{M} \mathrm{NaOH}$.

Plant materials as coagulants offer several advantages over conventional coagulants such as aluminium sulphate as stated below. Activity is maintained over a wide range of influent $\mathrm{pH}$ values-no $\mathrm{pH}$ correction required; Natural alkalinity of the raw water is unchanged following coagulation-no addition of alkalinity required; Sludge production is greatly reduced and is essentially organic in nature with no aluminium residuals-sludge volumes are reduced by a factor of up to 5; Minimal coagulant dosage requirement; Efficiency at low temperature and Chemical coagulants are toxic, more costly and less biodegradable.

Many researchers carried out studies using Moringa seed for water and wastewater treatment on the seed itself and as cake powder. As the studies reported, the Moringa seeds have content of protein (26.50\%-32.00\%), fiber (5.80\%-9.29\%), ash (5.60\%-7.50\%), fat $(42 \%-45 \%)$ and moisture contents $(8.7 \%-9.1 \%) .{ }^{11}$ It is also stated that Moringa seeds as one of the most effective natural coagulants, used to transform water constituents into forms that can be separated out physically. Considerable quantities of high molecular weight water-soluble proteins present in the seed of Moringa bring a positive charge. When the crushed seeds added to water, the protein produces positive charges acting like magnets and attracting the predominantly negatively charged particles. Under proper agitation, these bound particulates grow in size to form the flocs, which may be removed by filtration or left to settle by gravity. ${ }^{12}$ In developing countries, Moringa seed is considered favorably in terms to reduce the costs of wastewater treatment in comparison with chemical coagulants. ${ }^{12-14}$

In addition, the sludge produced by Moringa seed as a coagulant is stated to be innocuous and 4-6 times less in volume than the chemical coagulants produced. In the present attempt, a study has been carried out systematically to assess the efficacy of colour removal in textile waste water containing some anionic dyes such as direct and reactive dyes which are most widely used for coloration of cotton, using Moringa stenopetala seed extracts as coagulant.

\section{Materials and methods}

\section{Materials}

Domestic mill for grinding the seeds in to powder, nylon sieve filter, Whatman filter paper 4, digital $\mathrm{pH}$ meter, UV spectrophotometer (Perkin Elmer, Model Lambda 2500), and Moringa seed were used during the experiment work. The HI93703 Turbidity meter was used to measure turbidity as per ISO 7027 Method. The dyes used in this study were Direct Blue/ Red, Reactive Red/ Blue and a mixture of both dyes; such as C.I Direct Red 81 ( $\lambda \max 497 \mathrm{~nm})$, C.I Direct
Blue 86 ( $\lambda \max 346 \mathrm{~nm})$, C.I Reactive Blue 19 ( $\lambda \max 315 \mathrm{~nm})$ and C.I Reactive Red 195 ( $\lambda \max 532 \mathrm{~nm})$. Finally, all dyes are mixed together simultaneously with themselves $(\lambda \max 362 \mathrm{~nm})$ and with industrial wastewaters obtained from Bahir Dar Textile Share Company, Bahir Dar, Ethiopia $(\lambda \max 333 \mathrm{~nm})$. Various chemicals as presented in Table 2 for making the buffer solutions of different $\mathrm{pH}$, Sodium chloride and ethanol for Moringa seed extraction, were used.

\section{Methods}

Moringa (M. Stenopetala) seed collection: Moringa seed were collected manually from the dried pods of trees. The seeds were dried in sun light for three dyes. The hull was removed from the seed surface and wings from the kernels after drying. The kernels were ground in to medium fine powder with a domestic mill to get solubilization of active ingredients in the seed.

Coagulant extracts: It is possible to use the Moringa seed as coagulant either as seed or extracting the oil from the seed (defatted cake). To enhance effectiveness on wastewater treatment, some studies have recommended the importance of using defatted Moringa seed. ${ }^{15}$ In line with this recommendation; defatted Moringa seed was prepared for the purpose of this study. Extracts were prepared by two methods such as a simple extract with distilled water and a saline extract with sodium chloride, as explained below.

\section{Simple extract}

Production process of simple extract coagulant: Grinding of dry seed without shell $\rightarrow$ aqueous dissolution of seed in distilled water $\rightarrow$ stirring $\rightarrow$ filtration

To prepare 1 Liter of simple extract coagulant in aqueous solution, 50 gram of seed powder was dissolved on 1 Liter of distilled water by mixing using magnetic stirrer for $45 \mathrm{~min}$ at room temperature. Then, the mixture was filtered through commercial filter paper on a funnel and again filtered through fine- filtering system (Whatman filter paper). The result was milk- like liquid and was used as coagulant without further purification.

\section{Saline extract}

Production process of saline extract coagulant: Grinding of dry seed without shell $\rightarrow$ Dissolution of seed in a solution of $0.5 \mathrm{M} \mathrm{NaCl}$ $\rightarrow$ Stirring $\rightarrow$ Filtration

To prepare $1 \mathrm{~L}$ of saline extract coagulant in aqueous solution, $50 \mathrm{~g}$ of powder were dissolved on $1 \mathrm{~L}$ of $\mathrm{NaCl} 0.5 \mathrm{M}$ solution by mixing vigorously at $\mathrm{pH} 7$ for $45 \mathrm{~min}$ in a magnetic stirrer at room temperature. Then, the mixture was filtered through commercial filter paper on a funnel and again filtered through a fine- filtering system (Whatman filter paper). The result was milk- like liquid and was used as coagulant without further purification. After, the seeds kernel dried, a domestic mill was used to grind in to fine powder to get solubilization of active ingredients in the seed. The extract oil was soaked in $95 \%$ ethanol, $100 \mathrm{~g}$ of the powder in $500 \mathrm{ml}$ of ethanol for 45 minutes at room temperature while mixed with the help of stirrer from time to time. To obtain the defatted cake, it was required to filter the solution using filter paper. The remaining solids (pressed cakes) in the filter were then dissolved in water followed by stirring and filtration in the same way. Then the cake was allowed to dry in oven at $40^{\circ} \mathrm{C}$ for 24 hours. In that process ethonal got rem oved from the seed cake powder. Finally, the dried seed powder is stored under room temperature until it is used for coagulation experiments (Figure 1). 

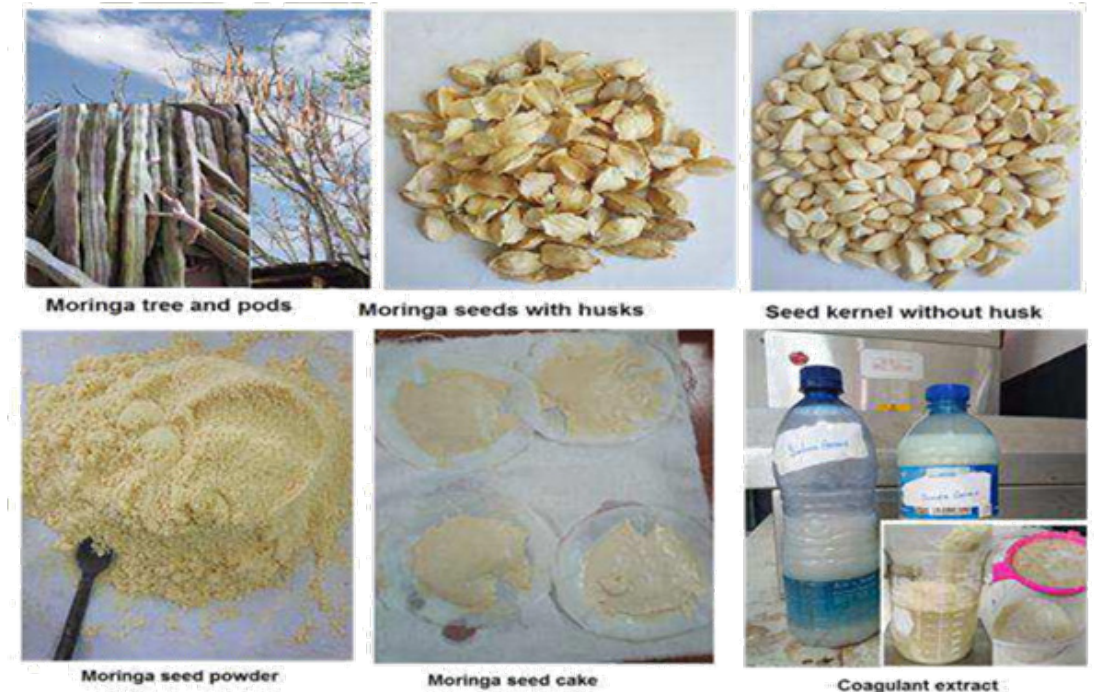

Moringa seeds with husks

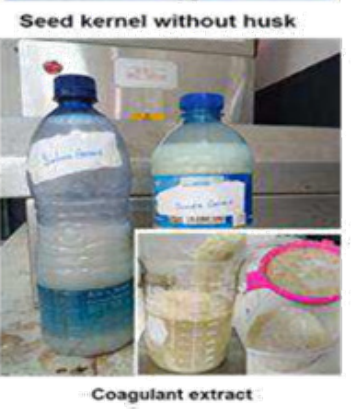

Figure I Elaboration of coagulant extract.

\section{a. Yield of Moringa seed in coagulant preparation}

The yield is calculated as given in equation (1).

$$
\text { Yieldofmoring } a=\frac{M_{i}-M_{f}}{M_{i}} * 100
$$

Where $M_{i}$ is the original weight of Moringa powder; $M_{f}$ is the Final weight of Moringa powder after filtration (un dissolved solids in the solution).

\section{b. Preparation of synthetic Effluent samples}

In order to test the coagulants extracts, in a first stage, synthetic samples were prepared in the laboratory using two types of dyes, all are azo type but with a classification of different class; direct and reactive dye; tested individually and as mixtures and with industrial wastewater, and mixture of dyes added to industrial waste water. The dye stock solutions were prepared by dissolving accurately weighed dyes between $100-300 \mathrm{mg} / \mathrm{L}$ water concentration, then dyeing with $100 \%$ cotton fabric sample following the standard procedures was carried out and dye waste water was collected after dyeing. Different concentrations were prepared from collected dye waste $(250,500$, $1000 \mathrm{ml}$ in beakers) for treating with coagulant.

\section{c. Effluent analysis}

Total solids, dissolved solids, suspended solids, BOD5, COD were measured following standard procedure (AMHA, 1995 and Standard methods, 1995) and SPSS Statistical Data Analysis Software was used for analyzing the data.

\section{d. Optimisation of process parameters}

In order to optimize the various process parameters, coagulant dosage range of $10-80 \mathrm{ml} / \mathrm{L}$, mixing time of $30-45$ minutes, $\mathrm{pH}$ in the range of 2-12 were used.

\section{e. Colour measurements}

The difference in absorbance before and after treatment measured in UV-VIS spectrophotometer was used for measurements of colour removal. The results are presented as graphs with respect to various process parameters. The Colour removal efficiency percentage of the parameters was calculated using the following formula (2).

$$
\text { Colour Removal efficiency }=\frac{A_{0}-A}{A_{0}} * 100
$$

Where $\mathrm{A}_{\mathrm{o}}$ is Absorbance value before treatment and $\mathrm{A}$ is Absorbance value after treatment.

\section{Results and discussions}

\section{Yield of extracts}

It has been observed that the yield of moringa seed powder dissolved in the solution is $93.4 \%$ and $92.5 \%$ for simple and saline extracts respectively. There was no significant difference between the extraction methods in terms of yield and it is evident that maximum percentage of Moringa powder is going to be consumed by the water and used wastewater treatment in the studies by dissolution.

\section{Characteristics of raw textile effluent}

An initial experiment was carried out to determine the preliminary characteristics of textile effluent for examining the effectiveness of the M. stenopetala as a coagulant. The effluent $\mathrm{pH}$ was found to be in the range of $\mathrm{pH} 9$ and 11.5 for all dye effluents and industrial wastewater having dyes Table 3 . This indicated that the effluent/dye waste from the textile industry has more alkaline in nature. As the measurement shows, the total solids were found at maximum level of $9000 \mathrm{ppm}$ and $8000 \mathrm{ppm}$ for the two direct dyes Red 81 and Blue 86 respectively. It was decreased to $3575 \mathrm{ppm}$ and $3830 \mathrm{ppm}$ after treatment with simple extract and 3500 and 2200 in saline extract as shown in Table 3. In addition, the experiment also confirmed that the particles of TDS are higher than TSS in the textile wastewater samples. Furthermore, the experimental results of wastewater sample show COD higher than BOD5 values. This value indicates, textile wastewater contains high amount of non-biodegradables, 3 to 4 times 
than degradable organic matters. For instance, direct red 81 abd blue 86 have higher value of COD which is decreased to 750 and 190 respectively in simple extract. In the same way, the highest value of BOD5 was found at reactive 195 and blu 19 which was reduced to 180 and 205 respectively in simple extract. The reduction of COD and BOD5 was also observed in saline extract treatment. The treated effluent was characterized and the values of various parameters $(\mathrm{pH}$, Total Dissolved Solids, turbidity, BOD5 and COD) are compared with the raw effluent. The characteristics of raw textile effluent and after treatment with simple and saline extracts are summarized in Table $2 \& 3$. One liter of wastewater was used for the treatment from the total solution. All samples have been mixed for 30-45minutes. The following table shows that, less removal of Turbidity, TS, COD and BOD5 for Industrial wastes and the one mixed with dye solutions waste water due to plenty of other components of wastes in industrial wastewater.

Table 2 Characteristics of raw effluent

\begin{tabular}{lllllll}
\hline Parameters/dye & Reactive red 195 & Reactive blue 19 & Direct red 8I & Direct blue 86 & $\mathbf{X}_{\mathbf{1}}$ & $\mathbf{X}_{2}$ \\
\hline Turbidity, FTU & 32.5 & 223 & 75 & 67 & 72 & 98 \\
TDS, mg/L & 5320 & 4500 & 5450 & 4670 & 4300 & 5200 \\
TSS, mg/L & 2180 & 2300 & 3550 & 3330 & 1300 & 3650 \\
TS, mg/L & 7500 & 6800 & 9000 & 8000 & 5600 & 8850 \\
COD, mg/L & 1600 & 2350 & 1810 & 1200 & 1700 & 2200 \\
BOD5, mg/L & 1270 & 900 & 1080 & 960 & 1160 & 1180 \\
PH & 11.5 & 10.9 & 9.8 & 9 & 11.3 & 11 \\
\hline
\end{tabular}

$X_{1}$, mixed all dye solution; $X_{2}$, industrial wastewater with dye solution

Table 3 Characteristics of Simple and Saline extracts' treated Effluents

\begin{tabular}{|c|c|c|c|c|c|c|c|c|c|c|c|c|}
\hline \multirow{2}{*}{ Parameters/dyes } & \multicolumn{2}{|c|}{ Reactive red 195} & \multicolumn{2}{|c|}{ Reactive blue 19} & \multicolumn{2}{|c|}{ Direct red 8I } & \multicolumn{2}{|c|}{ Direct blue 86} & \multicolumn{2}{|l|}{$x_{1}$} & \multicolumn{2}{|l|}{$\mathbf{x}_{2}$} \\
\hline & SiE & SaE & SiE & SaE & SiE & SaE & SiE & SaE & SiE & SaE & SiE & SaE \\
\hline Turbidity, FTU & 20.25 & 25.7 & 34.5 & 73 & 52 & 46.4 & 38 & 48.3 & 50 & 40 & 63.7 & 59.5 \\
\hline TDS, mg/L & 2010 & 2150 & 1690 & 1900 & 1875 & 1500 & 1770 & 1250 & 140 & 1100 & 2060 & 1900 \\
\hline TSS, mg/L & 1060 & 1300 & 900 & 1130 & 1700 & 2000 & 2060 & 950 & 820 & 480 & 1650 & 1700 \\
\hline $\mathrm{TS}, \mathrm{mg} / \mathrm{L}$ & 3070 & 3450 & 2590 & 3230 & 3575 & 3500 & 3830 & 2200 & 222 & 1580 & 3710 & 3600 \\
\hline COD, mg/L & 350 & 380 & 645 & 460 & 750 & 825 & 190 & 205 & 230 & 270 & 810 & 834 \\
\hline BOD5, mg/L & 180 & 175 & 130 & 165 & 95 & 110 & 210 & 185 & 205 & 200 & 200 & 240 \\
\hline $\mathrm{pH}$ & 9.5 & 8.9 & 9.5 & 8.7 & 7.5 & 7.2 & 7.9 & 7.7 & 8.8 & 8.8 & 9 & 9 \\
\hline
\end{tabular}

$\mathrm{SiE}$, simple extract; $\mathrm{SaE}$, saline extract; $\mathrm{X} 1$, mixed all dye solution; $\mathrm{X} 2$, industrial wastewater with dye solution

The effects of processing parameters on coagulation effect of coagulant dose

Coagulant dosage is one of the most significant parameters that have been considered to find out the optimum condition for the performance of coagulants in coagulation and flocculation.

The coagulant dosage indicates the concentration of M. stenopetala seed extract in the water. This difference is important to note since a lot of the seed mass was separated during the filtration step when preparing the extract. Basically, insufficient dosage or overdosing would result in the poor performance in flocculation. Thus, it is significant to determine the optimal dosage in order to reduce the dosing cost and sludge formation and also to get the optimal performance in treatment. The effect of coagulant doses $(10-80 \mathrm{ml} / \mathrm{L})$ on the removal of reactive and direct dyes using Moringa stenopetala coagulant and flocculation time is $30-45 \mathrm{~min}$ is shown in Figures $2-5$.
This shows that there was continuous removal of these dye colours with increasing coagulant doses up to $70 \mathrm{ml} / \mathrm{L}$ as shown in Figure $2 \& 3$. After $70 \mathrm{ml} / \mathrm{L}$, the colour removal decrease that confirms the optimal concentration as $70 \mathrm{ml} / \mathrm{L}$. This shows a result of re-suspension of solids at this concentration. Furthermore, the high concentrations greater than $25.0 \mathrm{mg} / \mathrm{L}$ of coagulant confer positive charges on the particle surface (a positive zeta potential), thus re- dispersing the particles.

It is also an assumption that an increase in the coagulant dose may cause a decrease in $\mathrm{pH}$ of system. The decrease in $\mathrm{pH}$ may be as a result of the hydrolysis of the coagulants. Low $\mathrm{pH}$ values of the coagulated system usually may be attributed to the neutralization of the negatively charged surfaces of wastewater colloids, leading to their destabilization by $\mathrm{H}+$ ions. However, acidification of coagulated wastewater may disturb sorption or could increase the solubility of freshly formed sludge. The highest percentage colour removal of 
these dyes was found to be $98.4,86,94.45,89.3,90.5$ and $85.8 \%$ and $97.3,84.45,96.6,84.8,87.73$ and $84.6 \%$ for Reactive red 195 , Blue19, Direct Red 81, Blue 86, Industrial waste water and the mixture for both simple and saline extract respectively. This confirms that Moringa seeds to have absorbent properties and effective for removal of colour.

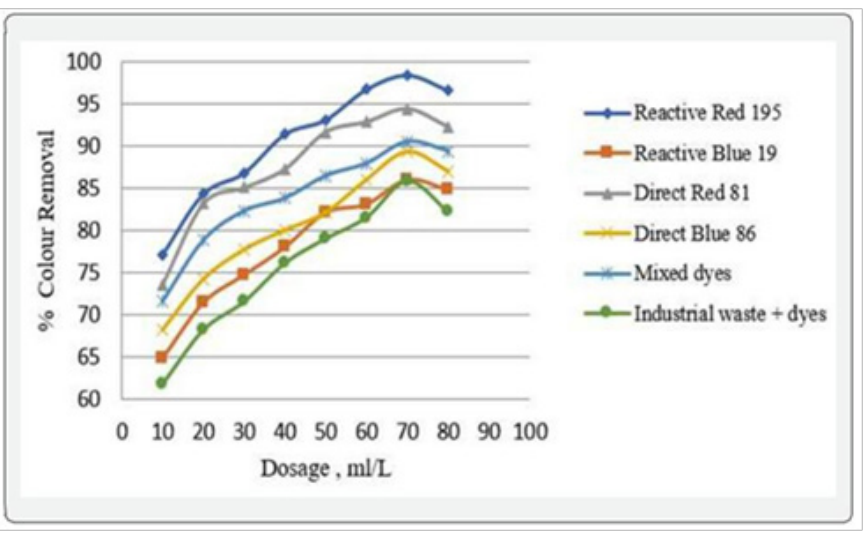

Figure 2 Percentages of colour removal in simple extract method.

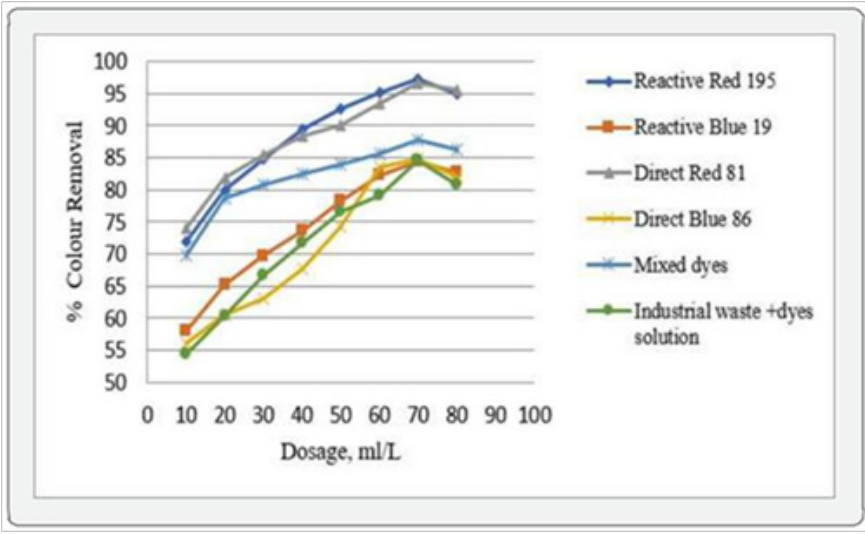

Figure 3 Percentages of color removal in saline extract.

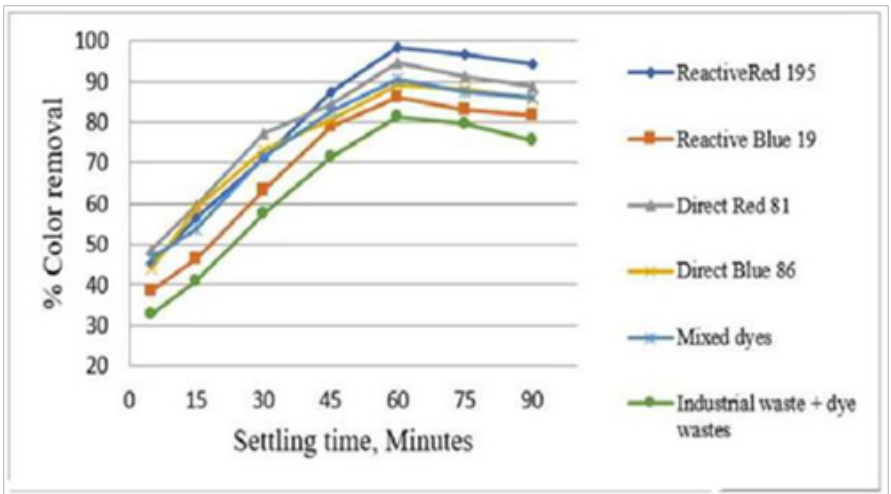

Figure 4 Percent of colour removal vs settling time.

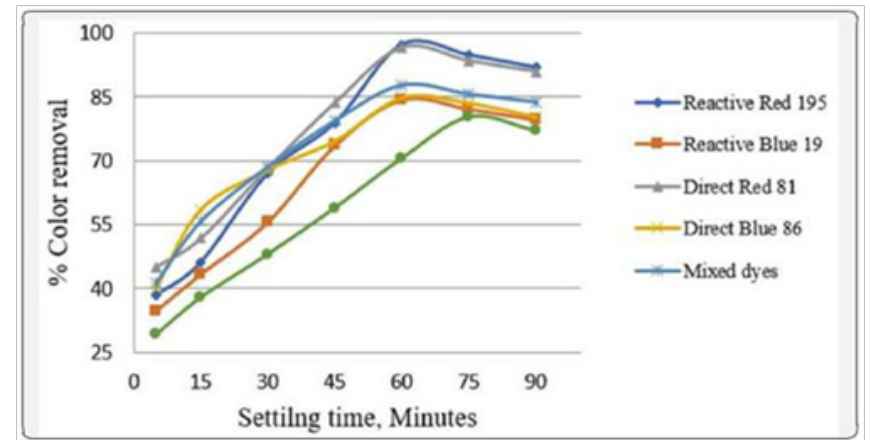

Figure 5 Percent of colour removal vs settling time for Saline extract.

\section{Colour removal}

After the characterization of the effluent, the prepared coagulants from the Moringa stenopetala seeds were added to the effluent in the form of coagulant to determine the effectiveness of the extract over the textile effluent. The result shows that the extract removes the turbidity and colour from the textile effluent. Removal efficiency of up to $98.4 \%$, for colour, was reached using $70 \mathrm{ml}$ Moringa Stenopetala coagulant extract. The use of Moringa seeds has an added advantage over the chemical treatment of water because it is biological and has been reported as edible. All dyes selected for this study, was prepared in the laboratory for treatments and also mixed with industrial wastewater. A dye solution was prepared as required and its $\mathrm{pH}$ was measured by using $\mathrm{pH}$ meter. One liter of the initial solution was transferred into two beakers and various doses of coagulant were added $(10,20,30,40,50,60,70$ and $80 \mathrm{in} \mathrm{ml} / \mathrm{L})$. The beakers were put one by one onto a standard magnetic stirrer. The solution was stirred for $10 \mathrm{~min}$ at high speed and slowly mixed at 60rpm for 30$35 \mathrm{~min}$. Later, the solution was left for settling around $45-60 \mathrm{~min}$. The supernatant after settling filtered through a Whatman filter paper (pore size $20-25 \mu \mathrm{m}$ ). Reduction in colour concentration was measured at maximum absorbency visible wavelength of each dye solution by using a UV-VIS spectrophotometer. The result of colour removal is shown in Figure 2\&3. In industrial wastewater colour removal is less because the effluent contains high content of dyestuff, surfactants and other additives that are generally made up of organic compounds with a complex structure. These wastewaters are collected from different sections having such different compounds and collected in wastewater plant for treatment.

\section{Effect of flocculation time}

The time of macro-floc formation (flocculation time) is one of the operating parameters that is given great consideration in any water treatment plant that involves coagulation-flocculation operations (Figure 4) (Figure 5). Presents the effect of flocculation time using different dose of coagulants for removal of reactive dyes, direct dyes, mixture of industrial wastewater, dyes of textile effluents. Consistence increment of removals has been revealed with increasing flocculation time up to $60 \mathrm{~min}$, and then it decreased. The optimum flocculation time was found to be $60 \mathrm{~min}$. The maximum removal of selected dye colours was found to be $98.4,86,94.45,89.3,90.5$ and $81.5 \%$ in reactive red, reactive blue, direct red, direct blue mixed dyes and 
mixture of dyes/and industrial wastewater respectively in simple extract at 60 minute. As well as, for saline extract the maximum colour removal was $97.3,84.41,96.6,84.887 .73$ and $80.3 \%$ in reactive red, reactive blue, direct red, direct blue, mixed dyes and mixture of dyes/ and industrial wastewater respectively.

Ebeling et al studied that the removal of Turbidity and Soluble Reactive Phosphorus (SRP, orthophosphate) was increasing as settling time increased from 5 to $45 \mathrm{~min} .{ }^{16}$ A series of jar tests were conducted to fetch the effect of settling time $(0,5,10,15,20,25$ and $30 \mathrm{~min}$ ) on the removal efficiencies of BOD5, COD and TSS using low alkalinity wastewater and the results show that the small particles settle out quickly within the first $5 \mathrm{~min}$, with little change in the values up to $15 \mathrm{~min}$. The differences in BOD5, COD and TSS removal were not significant after $20 \mathrm{~min}$ of settling as indicated by other studie ${ }^{17,18}$ The result of settling time is given below in Figure $4 \& 5$.

\section{Effect of mixing time}

Studies were made to find out the effect of mixing time variation on colour removal efficiency. Various mixing time ranging from 15 minutes to 60 minutes were maintained and the results were reported in Figure 6\&7. The experimental result shows that there was a continuous removal of colour, turbidity, TDS and TSS while increasing the mixing time from 15 to 45 minutes. Similar results are observed by Patel and Vashi for some other dyes. ${ }^{19}$ When the mixing time is less than 45 minutes, the collisions between coagulants and colloids are not efficient to precipitate suspended solids in wastewater On the other way, if the mixing time is greater than 45 minutes, it would lead to an increase in flocs breakage \& limit the size of the floc formed. As a result, small size flocs are not dense to settle down \& cause the sample to be turbid again. In sum, it is also found that the longer or shorter mixing time would result poor performance of the coagulant seed for binding and bridging. There were similar results in experiments made by other researchers. Initially at less contact time $(\leq 15 \mathrm{~min}$.) the maximum colour removal efficiency was achieved to only $63.6 \%$ and $63.7 \%$ for mixed dyes and reactive red respectively in both simple and saline extract methods respectively. But results show that when the reaction time was increased to 45 minutes, the efficiency was nearly $95 \%$ and it decreased when time increased was beyond 45 minutes. ${ }^{20,21}$

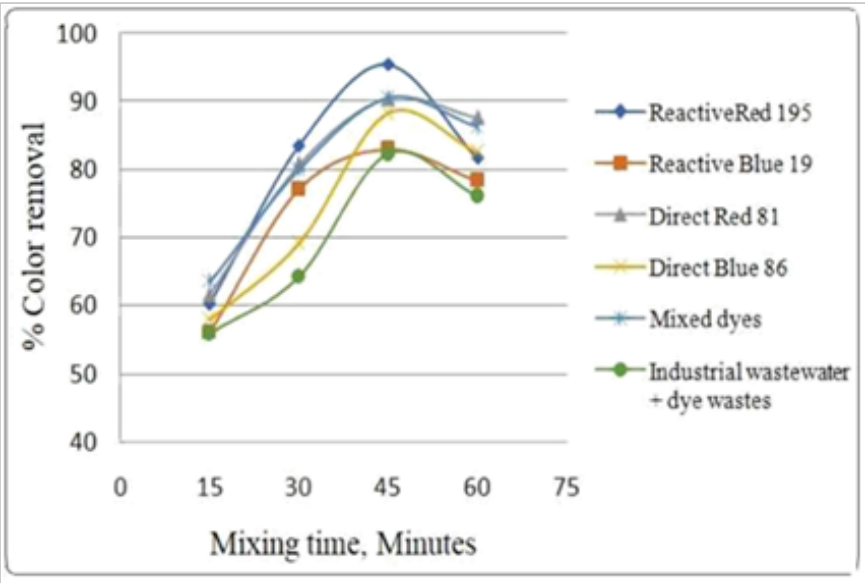

Figure 6 Percent of colour removal with mixing time in simple extract.

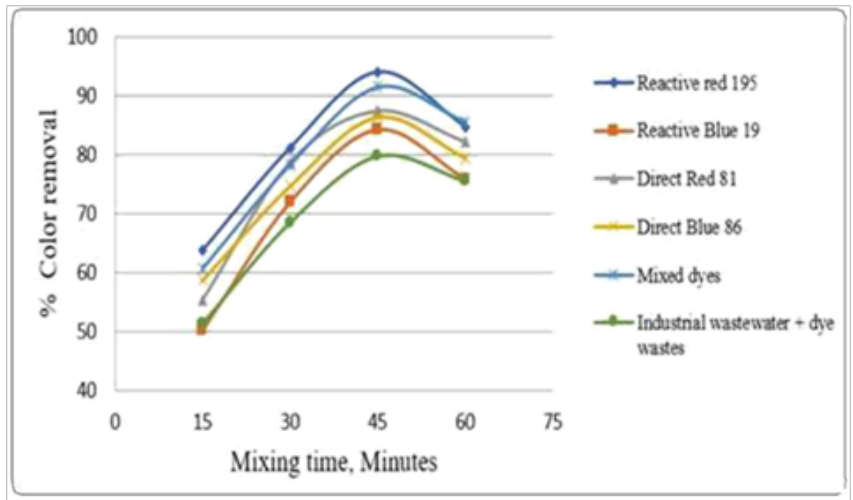

Figure 7 Percent of colour removal with mixing time in saline.

\section{Effect of $\mathrm{pH}$}

The aqueous solution of dye wastes was treated by constant concentrations of dose at $70 \mathrm{ml} / \mathrm{L}$ in dye wastewater of adsorbent for half a day with varying $\mathrm{pH}$ Between $2-12$. The $\mathrm{pH}$ was maintained with the help of buffer solutions. Figure 8 and Figure 9 shows, effect dye solution $\mathrm{pH}$ on the decolorization percent within the range of (212) for both simple and saline extract methods. The result showed that, decolorization reached maximum between $\mathrm{pH}$ 8-10 for both the selected dyes waste and industrial wastewater for all dosages. The effect of $\mathrm{pH}$ is crucial parameters to determine the optimum leveling order used to minimize the dosing cost and to get optimum performance in the treatment. In comparison, $\mathrm{pH}$ variation had a significant effect on the decolorization of reactive dye, direct dye and mixture of them with textile wastewaters by Moringa stenopetala seed extract.

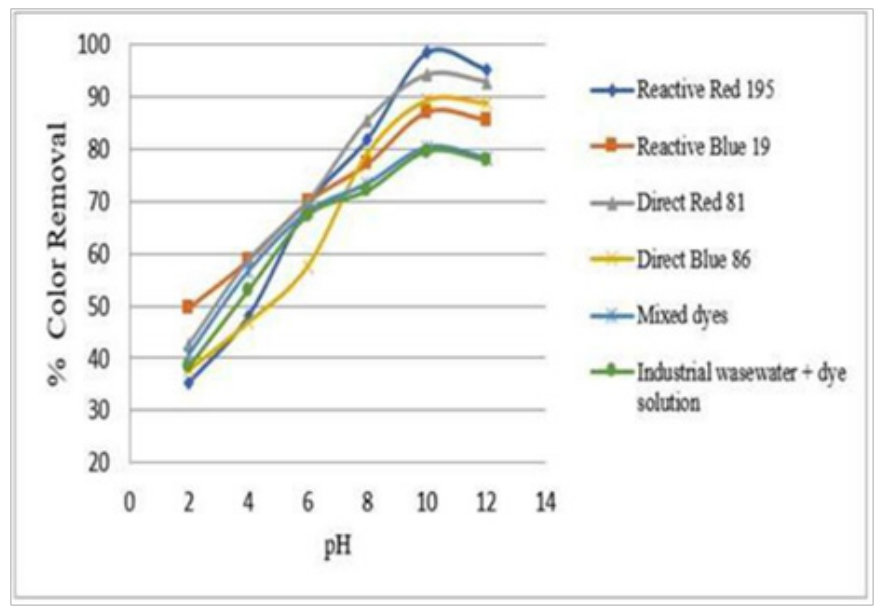

Figure $8 \mathrm{pH}$ Effect on colour removal under, Simple Extract.

From these figures, we can understand that the highest colour removal was at $\mathrm{pH} 10$ for all dye wastes. As $\mathrm{pH}$ increases from 2-10 the colour removal from textile wastewater increases. The removal of dyes are more at higher $\mathrm{pH} \mathrm{10,} \mathrm{because} \mathrm{the} \mathrm{surface} \mathrm{of} \mathrm{activated}$ coagulants are negatively charged, decrease in adsorption capacity at the low $\mathrm{pH}$ values would be expected as the acidic medium would lead to an increase in hydrogen ion concentration which would then neutralize the negatively charged coagulant surface thereby decreasing 
the adsorption of the positively charged ions because of reduction in the force of attraction between adsorbate and adsorbent. ${ }^{22-24}$

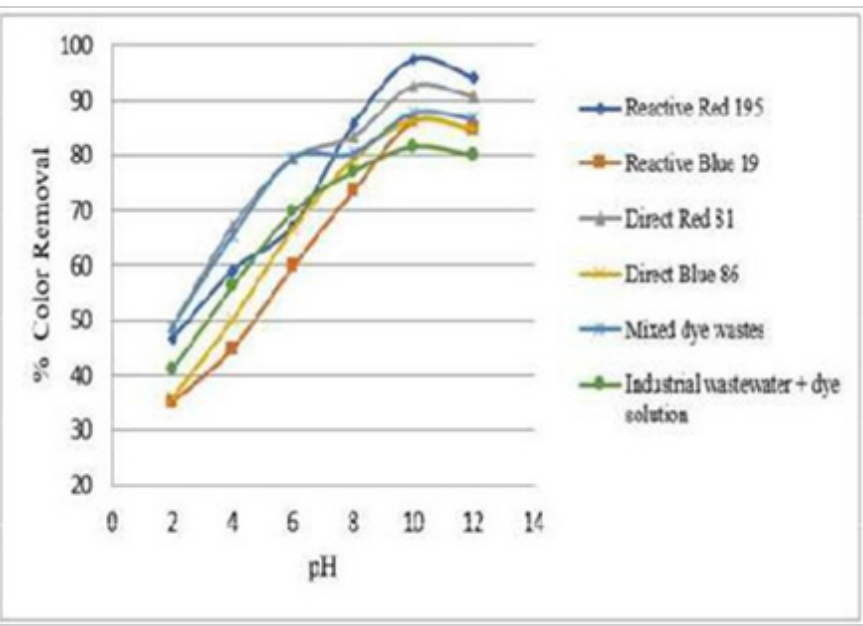

Figure $9 \mathrm{pH}$ effect on colour removal under, Saline Extract.

\section{Removal of turbidity}

Varying doses of the seed extract were added to the effluent followed by mixing at optimum time. The mixture was then filtered through filter paper, finally measure the turbidity value by turbidity meter. The result shows that the higher turbidity removal efficiency was obtained in simple extract method in the order of $84.6 \%$ and $83.7 \%$ in Saline extract methods for reactive blue dye (Reactive Blue 19) with the dosage of $70 \mathrm{ml} / \mathrm{L}$ as shown in Figure $10 \& 11$.

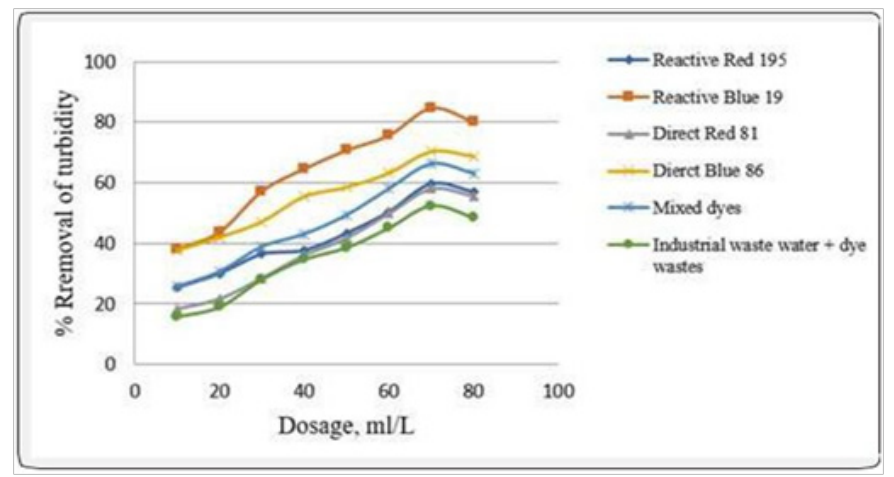

Figure 10 Percentage Turbidity removal Vs Dosage by Simple.

\section{Effect of dye types}

Comparative colour removal efficiency between reactive, direct dyes and mixture of them with industrial wastewater for both the dyes is shown as bar chart in Figure 12. The average colour removal efficiency of reactive dyes is higher than direct dyes, because reactive dyes are water dissolved due to the negative charge of the sulphonate group (SO3-) and direct dyes are the molecular structure with planar positive charges that are more than the negative charges and is water soluble. Direct dyes also have sulphonate (SO3-) functionality, but in this case, it is only to improve solubility, as the negative charges on dye and fibre will repel each other. The colour shade affects the efficiency of reactive colour removal of natural coagulant. In case of mixed dye, the averages of colour removal are found between reactive and direct dyes, because all reactive and direct dyes are mixed together and to have interchanging of all charges which affect colour removal.

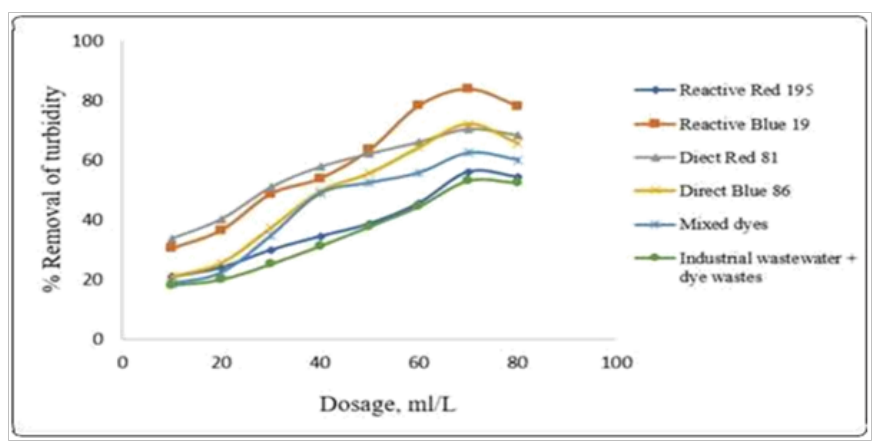

Figure II Percentage Turbidity removals Vs Dosage by Saline extract method.Figure 12 Effect of dye types on colour removal with Moringa seed

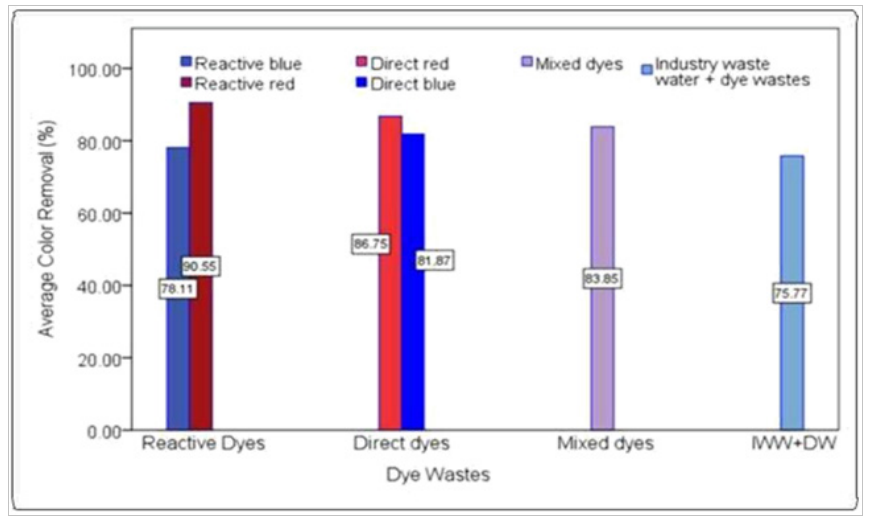

extract.

\section{Conclusion}

Moringa stenopetala seeds contain effective material as coagulant. Coagulant dose and coagulation $\mathrm{pH}$ are the most important factors influencing the mechanism of coagulation. Depending on dye type, the coagulation process varies. The optimized parameters for the coagulation of textile wastewater using $\mathrm{M}$. stenopetala were $\mathrm{pH} 10$ and dosage of $70 \mathrm{ml} / \mathrm{L}$ that can result in removal of 98.4 and $94.45 \%$ of colour in simple extract and 97.3 and $96.6 \%$ in saline extract in both reactive and direct red dyes respectively. Moringa seed can also remove the maximum turbidity of textile dye wastes to the tune of $85 \%$. It could be concluded that natural coagulant aid created a significant impact on the physical treatment of textile wastewater. The colour removal of mixture of industrial wastewater having reactive and direct dye solution was 85.8 and $84.6 \%$ in both simple and saline extract respectively because industrial effluent contains high content of dyestuff, surfactants and other additives that are generally made up of organic compounds with a complex structure while it is collected from different sections which use different compounds.

\section{Declarations: Not Applicable}

Data availability: All data used for the current study available online.

Funding: Ethiopian Institute of Textile and Fashion Technology covered funds for design of the study and collection, analysis, and interpretation of data. 
Authors' contributions: All Authors have equal contribution in the current study. They read and approved the final manuscript.

\section{Acknowledgments}

The Authors express their sincere thanks to Ethiopian Institute of Textile and Fashion Technology for the financial support to do this research.

\section{Conflicts of interest}

The authors declare that there is no conflict of interest.

\section{References}

1. Dias AA, Bezerra RM, Lemos PM. et al. In vivo and laccase- catalysed decolourization of xenobiotic azo dyes by a basidiomycetous fungus characterization of its ligninolytic system. World Journal of Microbiology and Biotechnology. 2003;19(9):969-975.

2. Beltrán Heredia J, Sánchez Martín J. Azo dye rem oval by Moringa oleifera seed extract coagulation. Coloration Technology. 2008;124(5):310-317.

3. Caudell M, Rotolo T, Grima M. Informal lending networks in rura Ethiopia. Social Networks. 2015;40(1):34-42.

4. Chen $\mathrm{C}$, Lu C, Chung Y, et al. UV light induced photodegradation of malachite green on $\mathrm{TiO}_{2}$ nanoparticles. J Hazar Mater. 2007;141(3):520 528

5. Freitas T, Oliveira V, De souza M, et al. Optimization of coagulationflocculation process for treatment of industrial textile wastewater using okra (A. esculentus) mucilage as natural coagulant. Industrial Crops and Products. 2015;76(8):538-544.

6. De Souza MTF, Ambrosio E, De Almeida CA, et al. The use of a natural coagulant (Opuntia ficus-indica) in the removal for organic materials of textile effluents. Environ monit assess. 2014;186(8):5261-5271.

7. De Souza MTF, De Almeida CA, Ambrosio E, et al. Extraction and use of Cereus peruvianus cactus mucilage in the treatment of textile effluents. Journal of the Taiwan Institute of Chemical Engineers. 2016;67(10):174 183.

8. Robinson T, Mcmullan G, Marchant R, et al. Remediation of dyes in textile effluent: a critical review on current treatment technologies with a proposed alternative. Bioresource technology. 2001;77(3):247-255.

9. Choy SY, Prasad KMN, Wu TY, et al. Utilization of plant-based natural coagulants as future alternatives towards sustainable water clarification. $J$ environ sci. 2014;26(11):2178-2789.

10. Choy S, Prasad K, Wu T, et al. A review on common vegetables and legumes as promising plant-based natural coagulants in water clarification. Int J Environ Sci Technol. 2015;12(1):367-390.

11. Anwar F, Bhanger M. Analytical characterization of Moringa oleifera seed oil grown in temperate regions of Pakistan. J Agric Food Chem. 2003;51(22):6558-6563
12. Muralimohan N, Palanisamy T. Treatment of textile effluent by natural coagulants in Erode District. Asian Journal of Chemistry. 2014;26(3):911914.

13. Ndabigengesere A, Narasia KS. Use of Moringa oleifera seeds as a primary coagulant in wastewater treatment. Environmental Technology. 1998;19(8):789-800

14. Araújo CS, Alves VN, Rezende HC, et al. Characterization and use of Moringa oleifera seeds as biosorbent for removing metal ions from aqueous effluents. Water Sci Technol. 2010;62(9):2198-2203.

15. Patel H, Vashi R. Removal of congo red dye from its aqueous solution using natural coagulants. Journal of Saudi Chemical Society. 2012;16(2):131136.

16. Ebeling JM, Sibrell PL, Ogden SR, et al. Evaluation of chemical coagulation- flocculation aids for the removal of suspended solids and phosphorus from intensive recirculating aquaculture effluent discharge. Aquacultural Engineering. 2003;29(1-2):23-42.

17. Banu R, Do K, Yeom I. Phosphorus removal in low alkalinity secondary effluent using alum. International Journal of Environmental Science \& Technology. 2008;5(1):93-98.

18. Patel H, Vashi R. Comparison of naturally prepared coagulants for removal of COD and color from textile wastewater. Global NEST Journal. 2013;15(4):522-528.

19. Abiyu A, Yan D, Girma A, et al. Wastewater treatment Potential of Moringa Stenopetala over Moringa Olifera as a natural coagulant, antimicrobial agent and heavy metal removals. Cogent Environmental Science. 2018;4(1):1-13.

20. Aziz HA, Alias S, Assari F, et al. The use of alum, ferric chloride and ferrous sulphate as coagulants in removing suspended solids, colour and COD from semi aerobic landfill leachate at controlled $\mathrm{pH}$. Waste Manag Res. 2007;25(6):556-565.

21. Jeon JR, Kim EJ, Kim YM, et al. Use of grape seed and its natural polyphenol extracts as a natural organic coagulant for removal of cationic dyes. Chemosphere. 2009;77(8):1090-1098.

22. Mishra A, Srinivasan R, Dubey R. Flocculation of textile wastewater by Plantago psyllium mucilage. Macromolecular Materials and Engineering. 2002;287(9):592-596.

23. Renault F, Sancey B, Charles J, et al. Chitosan flocculation of cardboardmill secondary biological wastewater. Chemical Engineering Journal. 2009;155(3):775-783.

24. Shamsnejati S, Chaibakhsh N, Pendashteh AR, et al. Mucilaginous seed of Ocimum basilicum as a natural coagulant for textile wastewater treatment. Industrial Crops and Products. 2015;69(1):40-47. 